\title{
Distributions and Incidences of Elementary School Children with Lactose Intolerance Symptoms after Drinking Milk in Korea
}

\author{
Ki-Hwan Kim, Ji-A Choi, Seung-Beom Kang, Kyung-Sang Lee, and Sung-Sik Yoon* \\ Division of Biological Science and Technology, Yonsei University, Wonju 220-710, Korea
}

\begin{abstract}
Milk contains a number of nutrients required for human growth and development, such as disaccharide lactose which is significantly contained in milk and dairy products. About two thirds of world populations are reportedly suffering from lactose intolerance after drinking milk. Lactose intolerance is defined as a maldigestion of lactose in the human intestine with typical symptoms of abdominal pains, bloating, and diarrhea. In this study, incidence of lactose intolerance has been investigated for the elementary school children for 1 year from July, 2010 to June, 2011. It is found that about $70 \%$ of the total elementary students have joined the school milk program. Out of 636 total students that participated in this study, 449 were from the metropolis, 85 from middle-sized city, and 102 from the small town including rural areas (small town/rural areas). For distributions of lactose intolerance, 154 students (24.2\%) were found to be positive among the total 636 subjects. Based on the size of the city, the symptoms were the most prevalent for the students in the small town/rural areas at $31.4 \%(32 /$ $102)$, followed by $30.6 \%(26 / 85)$ in middle-sized city, and $21.4 \%(96 / 449)$ in the metropolis. On the other hand, gender had no significant effect on the incidence of lactose intolerance, shown those for boys and girls were $24.8 \%$ (77/310), 23.6\% (77/326), respectively. Further research is needed to confirm the correct incidence of lactose intolerance symptoms as the frequency is significantly affected by subject's digestive functions including irritable bowel syndrome.
\end{abstract}

Key words: lactose intolerance, incidence rate, fresh milk, school children, breath hydrogen test

\section{Introduction}

Milk and dairy products are referred to as an almost complete food to human because protein, calcium, potassium, phosphorus, vitamin $\mathrm{B}_{2}$ (riboflavin), and many other nutrients are contained evenly. Especially, milk is recommended as the ideal food for young children. Lactose, a sort of disaccharide, is a source of energy contained in milk. It is hydrolyzed into glucose and galactose by lactase ( $\beta$-galactosidase) in the small intestine prior to absorption. Once lactose is absorbed in mucosa of small intestine, it is then in turn utilized to synthesize nondigestible galactooligosaccharides which promote growth of few probiotic bacteria and to improve gut microbiota by inhibiting the growth of harmful organisms in the intestine, promoting digestion and improving the health of the body. Lactose intolerance is clinically diagnosed with the breath hydrogen production test as well as intes-

\footnotetext{
*Corresponding author: Sung-Sik Yoon, Division of Biological Science and Technology, Yonsei University, Wonju 220-710, Korea. Tel: 82-33-760-2251, Fax: 82-760-5576, E-mail: sungsik (a)yonsei.ac.kr
}

tinal biopsy in clinical practice (Maffei et al., 1977). About $75 \%$ of the world's population genetically lacks innate ability to digest lactose. For the adults, phenotype of lactase persistence, which is able to hydrolyze lactose, is more common in the northern Europeans, but lactase non-persistence or adult-type hypolactasia is prevalent in the other areas (Arola, 1994). From the clinical point of view, physiological condition called lactase non-persistence is known as the lactose intolerance. Lactose intolerance is a congenital disorder of carbohydrate metabolism, caused by unabsorbed lactose in small intestine after when ingesting milk or dairy products containing lactose via osmosis caused by unabsorbed lactose in small intestine. As for the mechanism (Fig. 1), body fluids and electrolytes flow into the lumen and stimulate the nervous system of the small intestine due to hydrogen and methane, carbon dioxide, and others, finally leading to clinical symptoms such as diarrhea, flatulence, abdominal swelling, abdominal pain, and so on. It is commonly known to occur in adults more than children (Bedine and Bayless, 1973; Holsinger, 1978; McCracken, 1971; Paige and Bayless, 1975; Rosensweig, 1969; Savaiano and Leritt, 1987). As for the primary cause of lactose intolerance, an 


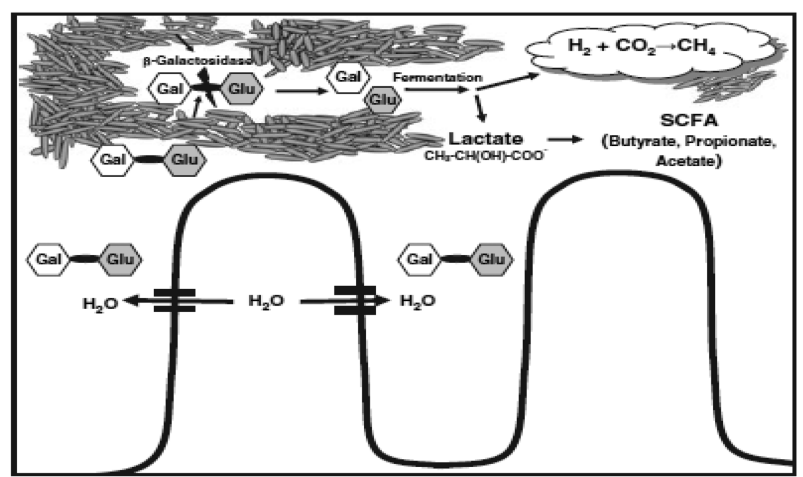

Fig. 1. Hydrogen gas generation process in the intestines (Lomer et al., 2008)

enzyme lactase produced naturally decreases with age. Lactase activity is usually highest in infancy, and then gradually decreases to, finally it reaches for adult to 5$10 \%$ of that level for adults in infancy (Hertzler and Savaiano, 1996; 1997). Based on the earlier studies (Sahi, 1994; Scrimshaw and Murray, 1988), incidence of lactose intolerance in all of the world was reported to exceed $50 \%$ in Africa (Tsega, 1989), and almost 100\% in several Asian countries (Andersen and Barfoed, 1978; Simoons, 1978; Tadess, 1992). In the U.S., the difference in incidence rate by its racial difference was observed across racial groups. $15 \%$ of whites, $53 \%$ of Mexicans, and 80 $90 \%$ of blacks were positive in lactose intolerance test. In Europe, 2\% in Northern Europe and Scandinavia, -70\% in Italy and Sicily were reported to be lactose intolerant, showing significant difference across geographical locations. Many methods have been developed to diagnose lactose intolerance in an objective and scientific way, none is perfect but the hydrogen breath test (or breath hydrogen test), has been the current method of choice in many countries (Maffei et al., 1977).

This study was conducted to obtain basic information about distributions and incidence of lactose maldigestion or lactose intolerance symptoms for elementary school children in Korea.

\section{Materials and Methods}

\section{Selection of subjects}

Elementary school children (10-13 years old) were chosen as subjects who have with no medical history, especially family history of gastrointestinal disease. It was also excluded students with diabetes, use of antibiotics (within $3 \mathrm{wk}$ ), and abdominal surgery. This study has been conducted for 1 year from July, 2010 to June, 2011. Each student was allowed to take participate in this experiment by parents' consent. We are fully understand the experimental ethics guidelines for human subject under KFDA, Korea.

\section{Determination of lactose intolerance}

After fasting at least $12 \mathrm{~h}$ before the test, all of the subjects were given $400 \mathrm{~mL}$ of a full-fat fresh milk product (200 $\mathrm{mL} \times 2$, Maeil Dairy Co., Korea) adjusted to $20-25^{\circ} \mathrm{C}$ and consumed in $30 \mathrm{~min}$. Lactose intolerance was judged by two methods as described below.

\section{1) Lactose intolerance by questionnaire}

Questionnaire sheet (Appendix) was given to the subject to answer the 20 itemized questions about symptoms which he or she had before and after drinking fresh whole milk: "Not at all" was worth 1 point, "No" 2 points, "I'm not sure" 3 points, "Ordinary" 4 points, "A little" is 5 points, and "Extremely" 6 points (Matthews et al., 2005). Points of each answer were added and recorded to use statistical analysis. If the total score was above 60 points over the all of questions, then the result was recorded positive for the lactose intolerance test.

2) Test for breath hydrogen concentration $\left(\mathrm{H}_{2}\right.$ breath test)

Hydrogen concentration was measured in the expiration gas before and after drinking milk ( $2 \mathrm{~h}$ interval) using Gastrolyzer (Gastro ${ }^{+}$, England). Lactose intolerance test was diagnosed positive when the scores obtained by two individual measurements increased by more than $15 \mathrm{ppm}$ (Fig. 2).

\section{Statistical analysis}

The standard $t$ - and $\chi$-square-tests were used to test differences between experimental groups (Lovelace and Barr, 2005). The effects of certain background factors

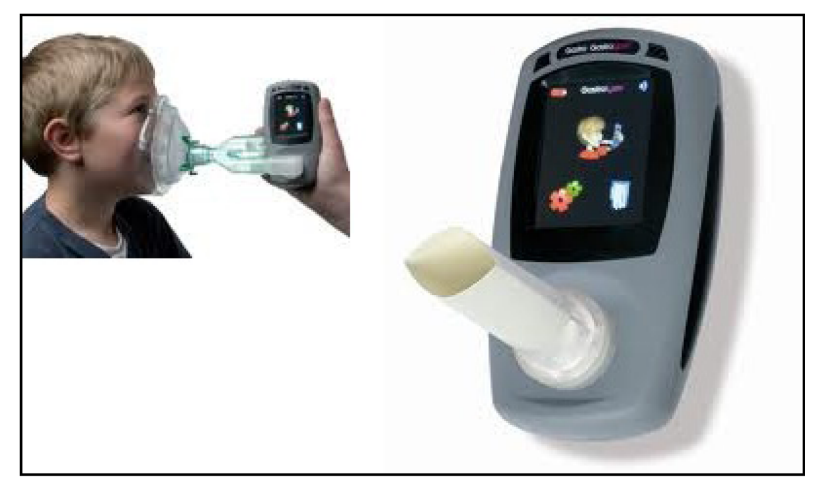

Fig. 2. Gastrolyzer (Gastro ${ }^{+}$, Bedfont, England) for breath hydrogen concentration test 
(sex, age, city size, and milk consumption) were taken into account, when the each groups were compared. Statistical analyses were performed with the SPSS package program (http://www.ibm.com) was used for statistical processing, analysis, and frequency of non-continuous variables, such as general information. A difference was considered to be statistically significant if $p$-value was less than 0.05 . For convenience, we made all of the data were graphed.

\section{Results}

For 636 elementary school students, lactose intolerance was examined according to the test method using the questionnaire (Fig. 3A), the incidence rate was resulted in $20.0 \%$ in the metropolis, $14.1 \%$ in middle-sized city, and $20.6 \%$ in the small town/rural areas (Fig. 3B). In addition, the breath hydrogen test (Fig. 4) produced the incidence rate of $10.5 \%$ in the metropolis, $20.0 \%$ in the middlesized city, and $12.2 \%$ in the small town/rural areas (Fig. 4A). Lactose intolerance from breath hydrogen test were not existed at the middle-sized city $\mathrm{A}$ and the metropolis

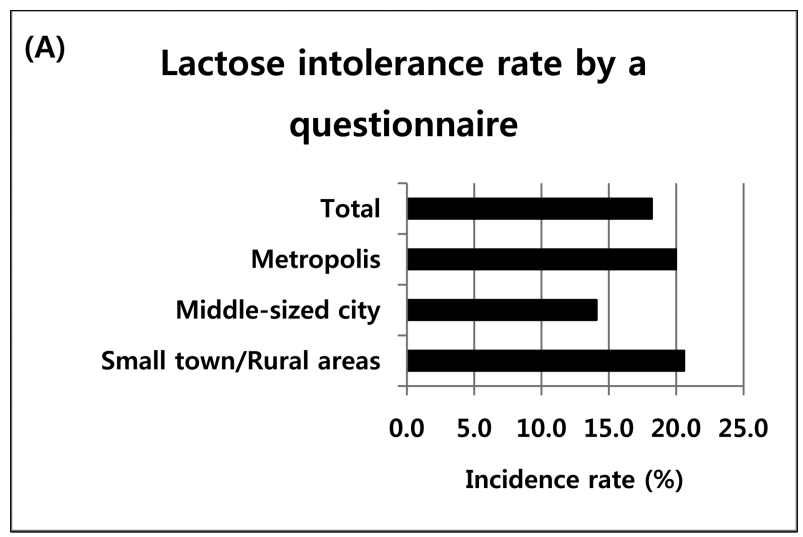

(B)

Lactose intolerance rate by a questionnaire

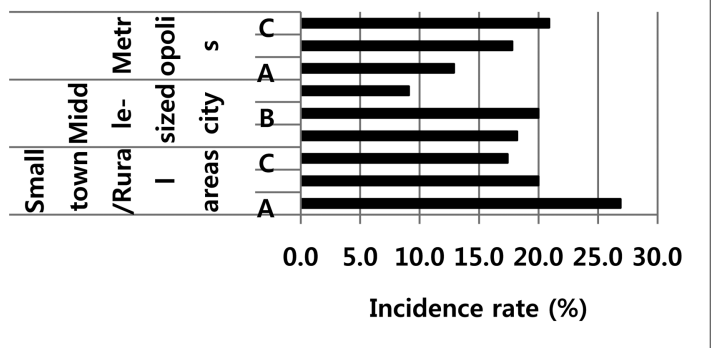

Fig. 3. The results of lactose intolerance rate by a questionnaire: The comprehensive of each result $(A)$, The results of each test group (B). ${ }^{*} \mathrm{~A}, \mathrm{~B}, \mathrm{C}$ are individual area according to city size.
$\mathrm{C}$, because there was no different each other. When the results by the questionnaire are combined with those by the breath hydrogen test, overall positive percentage of lactose intolerance was $21.4 \%$ in the metropolis, $30.6 \%$ in the middle-sized city, and $31.4 \%$ in the small town/rural area (Fig. 5). This result is almost consistent with the earlier publication by Kim (1994). There is no significant difference between the middle-sized city and the small town/rural areas. However, the overall frequency in the metropolis was approximately $10 \%$ less than those at the middle-sized city and the small town/rural areas (Fig. 5A). Fig. 5B showed the fluctuations of lactose intolerance rate according to the elementary school students in the three different geographical locations.

On the other hands, gender slightly affected the frequency: a $24.8 \%$ for boys and a $23.6 \%$ for girls (Fig. 6). This result was significantly lower than the previous study (Kim, 1994), which showed incidence rate of male at $65.1 \%$, female at $67.5 \%$, and average at $66.3 \%$. As for the incidence changes across geographical locations, the probable reasons include diversification of food cultures according to increases per capita income ranges. The $p$ -
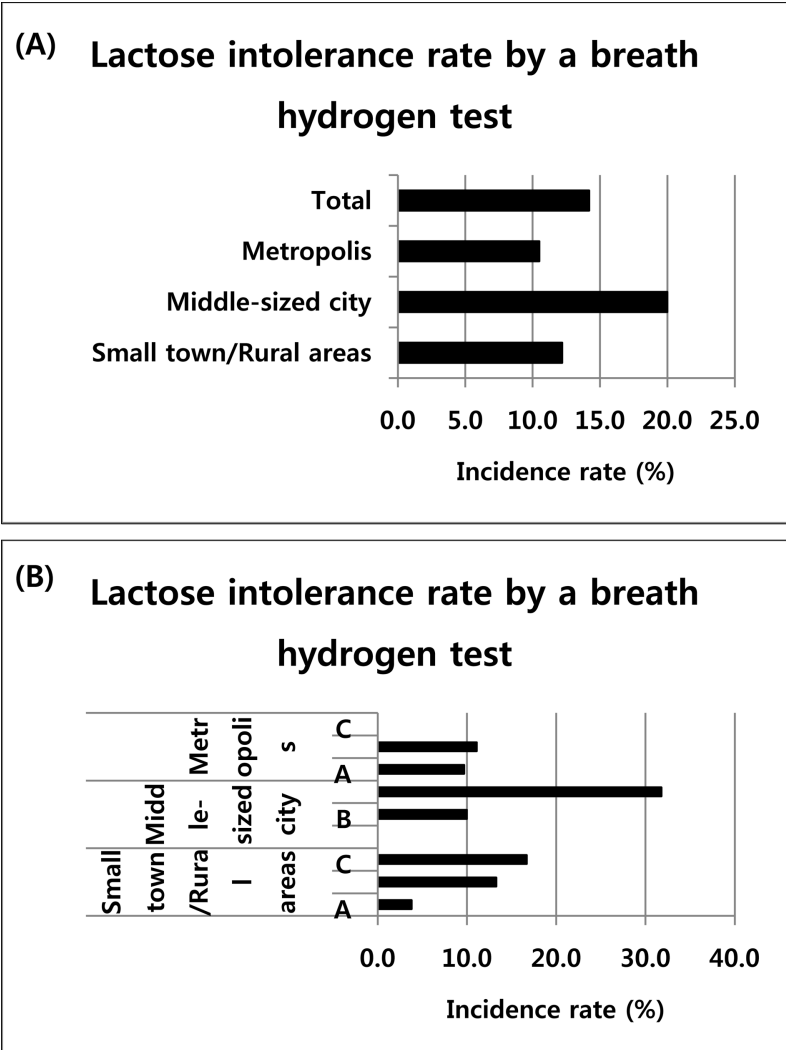

Fig. 4. The results of lactose intolerance with a breath hydrogen test: The overall results of each test(A), The results of each test group $(\mathbf{B}) .{ }^{*} \mathrm{~A}, \mathrm{~B}, \mathrm{C}$ are individual area according to city size. 


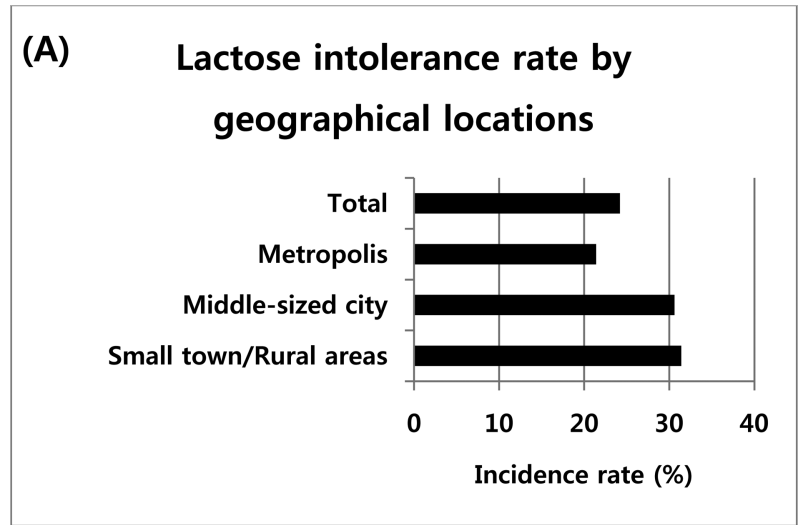

(B)

Lactose intolerance rate by geographical locations

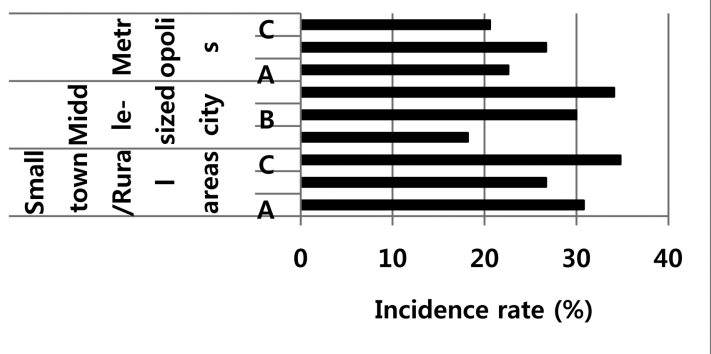

Fig. 5. Distributions of lactose intolerance in different geographical locations: The comprehensive of each result (5), The results of each test group (5). *A, B, C are individual area according to city size.

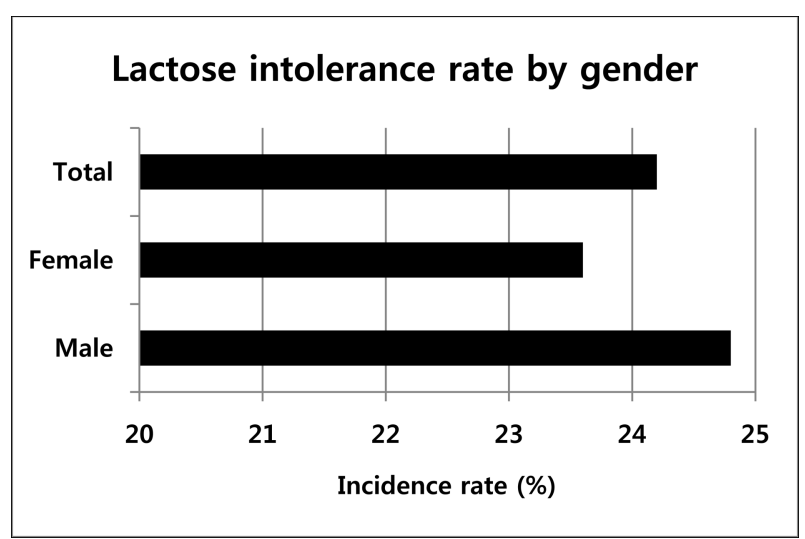

Fig. 6. Incidence rate of lactose intolerance according to the gender.

value obtained for gender was 0.986 and was not statistically significant at the $5 \%$ significance level $(p<0.05)$. Furthermore, the result based on city size was also not statistically significant at $5 \%$ significant level with the $p$ value of 0.135 at significance level $(p<0.05)$.

\section{Discussion}

Lactose in foods needs to be hydrolyzed prior to intestinal absorption. The hydrolytic enzyme responsible for splitting lactose into its monomeric forms, glucose and galactose, is called as lactase or $\beta$-galactosidase (Kretchmer, 1972). The former is primarily used as blood sugar and energy source and the latter used in glycolipid synthesis of brain tissues in infants. Genetic analysis of human lactase gene continued that lactase persistence was closely related to the err site of C/T-13910 single nucleotide polymorphism from the 5'-end (Kuchay et al., 2011). Frequency of lactose intolerance with conventional diagnosis is thought to be overestimated mainly because the subjects are exposed too much lactose of $50 \mathrm{~g}$ rather than a single serving quantity (Kim, 1994). Thus, simple and accurate diagnostic methods for lactose intolerance need to be established. It is admitted that frequency discrepancy between the two independent tests is present just because the difference could be present between the selfdiagnosed symptoms and those caused by lactose intolerance, and also account for the degree of symptoms felt by individual subject. The incidence changes in geographical locations include diversification of food cultures according to increases per capita income ranges, which provides ample opportunity to drink the milk and the expansion of school milk feeding. These results were similar to those from the earlier study (Johnson, 1987) of lactose intolerance that showed are regional differences among the Chinese in Taiwan and Hawaii, and also from the study (Cavalli-Sforza et al., 1987) of the variation of regional of lactose digestion in central, northern, and southern regions of Italy.

On the other hand, the incidence of lactose intolerance was not significantly different by gender. The typical symptoms were more severe in girls than boys when controlled for as for the same amount of milk-borne lactose. Reportedly, lactose maldigesters are defined as the person who suffers from clinical symptoms at $80-100 \%$ when consumed $50 \mathrm{~g}$ of lactose at once, and 1/3-1/2 of them has same symptoms appeared after drinking $200-250 \mathrm{~mL}$ of milk (Arola, 1994). Scrimshaw and Murray (1988) claimed that experimental incidence of lactose intolerance is more or less exaggerated than true incidence rate just because the popular protocol provides excessive amount of lactose $(50 \mathrm{~g})$, which is much higher amount of lactose than that (approximately $12 \mathrm{~g}$ ) contained in fresh milk usually consumed in daily life. According to the study about lactose intake and diarrhea in Japan, 
2006, incidence of diarrhea by daily increase of lactose intake from 30 to $60 \mathrm{~g}$ (by $10 \mathrm{~g}$ increment) for healthy people, who are free of the symptoms such as diarrhea, constipation, and gastrointestinal disorder, was not observed until $30 \mathrm{~g}$. However, the incidence rate increased from $11 \%$ at $40 \mathrm{~g}, 39 \%$ at $50 \mathrm{~g}$, and $55 \%$ at $60 \mathrm{~g}$. As most of Koreans usually drinks fresh milk less than $500 \mathrm{~mL}$ daily, which is equivalent to $25 \mathrm{~g}$ of lactose. It is reasonable to conclude that lactose in milk is not directly related to frequent incidence of diarrhea, especially for elementary school children in Korea.

\section{Acknowledgement}

This work was supported by the Korean Dairy Farmers' Pick-Off Fund Commission in Korea, 2010.

\section{References}

1. Alm, L. (1982) Effect of fermentation on lactose, glucose, and galactose content in milk and suitability of fermented milk products for lactose intolerant individuals. J. Dairy Sci. 65, 346-352.

2. Arola, H. (1994) Diagnosis of hypolactasia and lactose malabsorption. Scand. J. Gastroenterol. (Suppl.) 202, 26-35.

3. Bedine, M. S. and Bayless, T. M. (1973) Tolerance of small amounts of lactose by individuals with low lactose levels. Gastroenterol. 65, 733-742.

4. Cavalli-Sforza, L. T., Strata, A., Barone, A., and Cucurachi, L. (1987) Primary adult lactose malabsorption in Italy. Am. J. Clin. Nutr. 45, 748-754.

5. Feldman, H. and Gilat, T. (1971) A trial of deglycyrrhizinated liquorice in the treatment of duodenal ulcer. Gut 12, 449-451.

6. Hetzler, S. R. and Savaiano, D. A. (1996) Colonic adaptaion to daily lactose feeding in lactose maldigestion reduces lactose intolerance. Am. J. Clin. Nutr. 64, 232-236.

7. Hetzler, S. R. and Savaiano, D. A., and Levitt, M. D. (1997) Fecal Hydrogen production and Consumption Measurements. Response to daily lactose ingestion by lactose maldigesters. Dig. Dis. Sci. 42, 348-353.

8. Holsinger, V. H. (1978) Applications of Lactose-modified milk and whey. Food Technol. 32, 35-36.

9. Houts, S. S. (1998) Lactose intolerance. Food Technol. 42, 110-113.

10. Johnson, R. C., Ayau, E. P., Ching, C. A., Nagoshi, C. T., Yuen, S., Fjelstad, K., and Huang, Y. H. (1987) Environmental influences on lactose tolerance. Behav. Genet. 17, 313330.

11. Kretchmer, N. (1972) Lactose and lactase. Sci. Am. 227, 7178.
12. Kuchay, B. R., Thapa, A. Mahmood, and S. Mahmood. (2011) Effect of C/T 13910 cis-acting regulatory variant on expression and activity of lactase in Indian children and its implication for early genetic screening of adult-type hypolactasia. Clinica Chimica Acta 412, 1924-1930.

13. Lomer, M. C., Parkes, G. C., and Sanderson, J. D. (2008) Review article: lactose intolerance in clinical practice-myths and realities. Aliment Pharmacol. Ther. 27, 93-103.

14. Lovelace, H. Y. and Barr, S. I. (2005) Diagnosis, symptoms, and calcium intakes of individuals with self-reported lactose intolerance. J. Am. Coll. Nutr. 24, 51-57.

15. Maffei, H. V., Metz, G., Bampoe, V., Shiner, M., Herman, S., and Brook, C. G. (1977) Lactose intolerance, detected by hydrogen breath test, in infants and children with chronic diarrhea. Arch. Dis. Childhood 52, 766-771.

16. Mattews, S. B., Waud, J. P., Roverts, A. G., and Campbell, A. K. (2005) Systemic lactose intolerance : a new perspective on an old problem. Postgard. Med. J. 81, 167-173.

17. McCracken, R. D. (1971) Lactase deficiency: An example of dietary evolution. Curr. Anthropol. 12, 479-517.

18. Paige, D. M., Bayless, T., Huang, S.-S., and Wexler, R. (1975) Lactose hydrolyxed milk. Am. J. Clin. Nutr. 28, 818822.

19. Rosensweig, N. S. (1969) Adult human milk intolerance and intestinal lactase deficiency. J. Dairy Sci. 52, 585-587.

20. Savaiano, D. A., El Amouar, A. A., Smith, D. E., and Leritt, M. D. (1984) Lactose malabsorption from yogurt, pasteurized yogurt, sweet acidophilus milk, and cultured milk lactose-deficient individuals. Am. J. Clin. Nutr. 40, 1219-1223.

21. Savaiano, D. A. and Leritt, M. D. (1987) Milk intolerance and microbe-containing Dairy food. J. Dairy Sci. 70, 397406.

22. Sahi, T. (1994) Hypolactasia and lactase persistence: Historical review and the terminology. Scand. J. Gastroenterol. (Suppl.) 202, 1-6

23. Scrimshaw, N. S. and Murray, E. B. (1988) The acceptability of milk and milk products in populations with a high prevalence of lactose intolerance. Am. J. Clin. Nutr. 48, 10791159.

24. Simoons, F. J. (1978) The geographic hypothesis and lactose malabsorption: a weighing of the evidence. Digest Diseases 23, 963-980.

25. Tadess, K., Leung, D. T. Y., and Yuen, R. C. F. (1992) The status of lactose absorption in Hong Kong Chinese children. Acta-Paediatrica 81, 598-600.

26. Tsega, E., Endeshiaw, Y., Mengeska, B., and Teda, B. (1989) The role of milk and lactose intolerance in Ethiopian patients with nonulcer dyspepsia: a case control study. EthiopianMedical J. 27, 135-145.

27. Kim, J. W. (1994) Studies on the lactose intolerance of Korean. Korean J. Dairy Sci. 16, 105-114.

(Received 2011.11.1/Revised 2011.12.8/Accepted 2011.12.8) 


\section{Appendix}

Questionnaire form used in this study

\begin{tabular}{|c|c|c|c|c|c|c|c|}
\hline \multirow{2}{*}{ No } & \multirow{2}{*}{ Questions } & \multicolumn{6}{|c|}{ Score } \\
\hline & & $\begin{array}{l}\text { Not at all } \\
\text { (1 point) }\end{array}$ & $\begin{array}{c}\text { No } \\
\text { (2 points) }\end{array}$ & $\begin{array}{l}\text { I am not sure } \\
\text { (3 points })\end{array}$ & $\begin{array}{l}\text { Ordinary } \\
\text { (4 points) }\end{array}$ & $\begin{array}{l}\text { A little } \\
\text { (5 points })\end{array}$ & $\begin{array}{l}\text { Extremely } \\
\text { (6 points) }\end{array}$ \\
\hline 1 & $\begin{array}{l}\text { I have experienced diarrhea or } \\
\text { stomachache after drinking milk }\end{array}$ & & & & & & \\
\hline 2 & feel stomachache & & & & & & \\
\hline 3 & feel nausea & & & & & & \\
\hline 4 & fluttered heart & & & & & & \\
\hline 5 & dried mouth & & & & & & \\
\hline 6 & acidic belching & & & & & & \\
\hline 7 & muscular pain & & & & & & \\
\hline 8 & headache & & & & & & \\
\hline 9 & feel fatigue & & & & & & \\
\hline 10 & lack of concentration & & & & & & \\
\hline 11 & vomit & & & & & & \\
\hline 12 & feel motion sickness & & & & & & \\
\hline 13 & have constipation & & & & & & \\
\hline 14 & loose bowels & & & & & & \\
\hline 15 & gas in stomach & & & & & & \\
\hline 16 & borborygmus & & & & & & \\
\hline 17 & feel bloated & & & & & & \\
\hline 18 & break gas & & & & & & \\
\hline 19 & frequently urinate & & & & & & \\
\hline 20 & be convulsed & & & & & & \\
\hline 21 & describe other abnormalities & & & & & & \\
\hline
\end{tabular}

This form is filled out by individual subject at $2 \mathrm{~h}$ after drinking a $400 \mathrm{~mL}$ of fresh milk. 